\title{
E्己̌ruAão \\ Diretrizes Curriculares e Professores Formadores: que relação é essa?
}

\author{
Mara Rejane Vieira Osório' \\ 'Universidade Federal de Pelotas (UFPel), Pelotas/RS - Brasil
}

RESUMO - Diretrizes Curriculares e Professores Formadores: que relação é essa? Este texto, a partir de estudos foucaultianos, problematiza a relação entre professores formadores e as reformas curriculares realizadas em três licenciaturas de uma instituição universitária de ensino superior (IES) pública. Envolvidos em atender e gerenciar demandas internas e externas, esses professores estão se constituindo como novos sujeitos. Neste sentido, questões fundamentais (bem comum, pedagógicas, valores, metas cognitivas, complexidade política) têm perdido espaço e esse sujeito passa a tratar do seu trabalho de modo técnico/pragmático; nesse processo, parece se afastar das possibilidades de interferir na produção e discussão dos currículos das licenciaturas.

Palavras-chave: Currículo. Licenciatura. Professores. Reforma. DCN.

ABSTRACT - Curricular Guidelines and Professors: what relation is this? This text, based on Foucault's thinking, presents discussions about the working conditions of trainer professors and the implications for curricular reformulation in three bachelor's degrees (Social Sciences, Visual Arts and Physical Education). Involved to attend and manage internal and external demands, these professors are being constituted as new subjects. Thus, fundamental issues (common welfare, pedagogies, values, cognitive goals, political complexity) have been losing space and these subjects tend to deal with their work in a technical/pragmatic way; in this process, they tend to step back from the possibilities of interfering in the production and discussion of curriculums in the bachelor's degrees.

Keywords: Curriculum. Bachelor's Degree. Professors. Reformulation. DCN.

Educação \& Realidade, Porto Alegre, v. 43, n. 1, p. 171-186, jan./mar. 2018. 
Diretrizes Curriculares e Professores Formadores

\section{Introdução}

Este artigo trata da relação entre a política das diretrizes curriculares nacionais, que orientam o funcionamento das licenciaturas brasileiras, e os professores formadores, que são responsáveis por discutir, desenvolver, organizar e implementar os currículos nas instituições universitárias de ensino superior (IES). As Diretrizes Curriculares Nacionais para a Formação de Professores da Educação Básica (DCN) surgiram em 2002, trazendo, em seus discursos, o argumento de que um dos grandes problemas da Educação Básica é a frágil e atrasada formação inicial dos professores. Assim, seria necessária uma forte reforma dos currículos para resolver esse problema. Desde então, as IES foram obrigadas a fazerem as reformas curriculares e a implementarem nova dinâmica aos cursos de licenciatura.

Tendo em vista essas orientações oficiais, o grupo de pesquisa do qual faço parte tem acompanhado as reformas curriculares desde 2004, a partir de diferentes pesquisas, em uma IES pública. Este artigo é parte de um destes estudos que, financiado pela Fundação de Amparo à Pesquisa do Estado do Rio Grande do Sul (FAPERGS), buscou compreender que discursos e imagens sobre o professor, sua formação e sua profissão, circulavam em três cursos de licenciaturas (Ciências Sociais, Artes Visuais e Educação Física) de uma IES, após as reformas curriculares que foram implementadas por exigências das DCN. Contribuíram com o estudo 15 professores formadores que faziam parte dos Núcleos Docentes Estruturantes (NDE), incluindo os coordenadores. Foram estudados, ainda, os textos oficiais que tratam das diretrizes e os projetos pedagógicos dos cursos.

O trabalho seguiu pistas dos estudos de Foucault (1990; 2003; 2008a; 2008b) e Rose (1996; 1998; 2001); associou contribuições de estudiosos que percorrem esse mesmo caminho investigativo e que tratam de questões contemporâneas no campo da educação (Popkewitz, 1992; 1999; 2001; 2009; 2013; Ball, 1994; 2001; 2002; 2005; 2012; Garcia, 2001; 2002a; 2002b; Veiga-Neto, 2000; 2002; 2008). Estes pensadores vêm-se dedicando a problematizar as transformações contemporâneas mais gerais e seus impactos para as reformas, para as políticas educacionais e para conduta dos sujeitos (identidade e subjetividade).

Nesta perspectiva, compreende-se a política curricular e, também, os currículos das licenciaturas como tecnologias humanas, que, através de seus discursos e ações, criam demandas e racionalidades (significados, intenções e ações) para a formação de professores; ou seja, a política curricular e o currículo são pensados, no interior da problemática de governo da sociedade (ou da população), como tecnologias (de governo e produção de sujeito) inventadas para modificar as condutas das pessoas para as quais são dirigidas. Esse conceito de tecnologia é compreendido a partir de Rose (2001, p. 38), como “[...] qualquer agenciamento ou qualquer conjunto estruturado por uma racionalidade prática e governado por um objetivo mais ou menos consciente". Para atingir os objetivos desejados, cada tecnologia inventa, produz e coloca 
em movimento um conjunto de estratégias e práticas discursivas com a intenção de capturar sujeitos e direcionar suas condutas. Portanto, apoiada em Foucault (1990), é possível argumentar que a constituição de condutas é uma questão política de luta e de disputa pela produção de tipos de seres humanos desejáveis; ou seja, a conduta humana é um objeto de poder porque pode ser programada, modificada e transformada através de tecnologias e procedimentos. Com isso, ainda seguindo Rose (2001), não desejo argumentar que as tecnologias curriculares direcionadas para transformar as condutas dos professores são ruins ou malignas. Minha intenção é chamar atenção para aquilo que elas fazem, como o fazem, e para aquilo que produzem.

Uma questão que apareceu como fundamental, durante esta pesquisa, foi a relação entre o que é esperado da política curricular e os professores formadores que devem realizar as reformas. Observei que, quando se fala em reforma de currículo, em valorização das licenciaturas e em qualidade da formação, pouco se tem considerado sobre as condições locais que constituem a reforma dos currículos. As informações que apareceram neste estudo mostram que essa é uma questão que carece de maior atenção, problematização e análise, pois representa um fator importante para as tão desejadas reformas curriculares dos cursos de licenciaturas.

Neste sentido, o objetivo deste artigo é mostrar que as novas condições do trabalho docente, associadas às demandas das DCN, produzem, também, novas condições para os currículos das licenciaturas. Pergunto: - O que acontece nessa relação ou, mais especificamente, como aponta o título, diretrizes curriculares e professores formadores: que relação é essa?

Dentro dos planos estabelecidos no campo educacional, a política curricular cria as demandas reformadoras para os currículos de formação de professores e espera que cada instituição faça as reformas conforme as esperanças e os desejos fixados por esse instrumento oficial. Contudo, a pesquisa mostrou que isso não é tão fácil, pois, nessa relação, não existe uma condição linear de simples reprodução do texto (de suas esperanças e intenções); quando a política curricular entra em espaços locais, ela passa por transformações, adaptações e composições.

\section{Uma Relação Instável e Produtiva: DCN e professores formadores}

A partir da intensa circulação de discursos sobre a crise da educação movida, principalmente, pelas reformas neoliberais que se intensificam a partir dos anos de 1990, passou-se a acreditar que, ao transformar a formação do professor, seria possível, também, curar os males da Educação Básica e, consequentemente, da sociedade. No bojo desse senso comum, nos últimos anos, a formação de professores tem ganhado prioridade no espaço das políticas públicas educacionais e tem sido considerada, ao mesmo tempo, como vilã e heroína no campo da educação. 
A política curricular, conhecida como Diretrizes Curriculares Nacionais para a Formação do Professor da Educação Básica (DCN), deve ser considerada no interior desse quadro de pensamento. Esta política emerge apontando os currículos das licenciaturas como instrumentos condutores de mudanças, tanto na formação inicial quanto no trabalho do professor na Educação Básica. Como base curricular geral, foi conjugada em quatro documentos reguladores: o parecer do CNE/CP 09/2001 (Brasil, 2002a); o parecer CNE/CP 28/2001 (Brasil, 2002b) e as Resoluções CNE/CP 1/2002 (Brasil, 2002c) e CNE/CP 2/2002 (Brasil, 2002d), que fundamentam os dois pareceres.

No conjunto discursivo desses textos oficiais, percorrem promessas para resolverem problemas apontados como fundamentais da formação de professores: o distanciamento entre formação inicial superior e a educação básica, que tem resultado em desconsiderar as especificidades das etapas da educação básica e dos conhecimentos que constituem seus currículos; o isolamento das instituições formadoras; a baixa qualidade da formação dos professores; a desarticulação (fragmentação) entre teoria e prática; a desvalorização da pesquisa; a ausência da preparação para o uso de tecnologias de comunicação e informação; etc. Ou seja, como é salientado no parecer CNE/CP 09/2001 (Brasil, 2002a, p. 4), o grande problema a ser resolvido, no campo da educação, é o “[...] preparo inadequado dos professores cuja formação, de modo geral, manteve, predominantemente, um formato tradicional, que não contempla muitas das características consideradas na atualidade”. Segundo o texto, o problema existe pelas seguintes razões: os currículos de formação docente têm priorizado questões bastante teóricas e conteudistas, deixando marginalizadas as questões práticas e particulares da realidade escolar; os currículos estão desatualizados frente às exigências contemporâneas; as licenciaturas estão posicionadas como questão de segundo plano nas instituições formadoras, pois, ainda, são consideradas como apêndices dos bacharelados. A docência, diz o documento, deve ser, então, a base da formação, tendo, no horizonte, as mudanças na organização pedagógica e curricular da educação básica e articulando teoria e prática. A grande esperança contida no parecer do CNE é de que as diretrizes, como "[...] base comum de formação docente [...] possibilite a revisão criativa dos modelos [...] em vigor" (Brasil, 2002a, p. 5), e, assim, promova um conjunto de mudanças.

Contudo, quando um texto oficial entra no espaço local ele não cai num vazio; ao contrário, depara-se com tradição e estrutura institucional, condições de trabalho, natureza e cultura dos cursos, posição das licenciaturas no campo das profissões, tipos de sujeitos, formas de gestão, etc. Nessa relação entre o texto e os leitores do texto, a política ganha outros contornos, significados são alterados ou suprimidos, algumas questões são tomadas como importantes enquanto outras são desprezadas ou adaptadas para garantir tradição e pressão oficial. Com isso, quero defender, seguindo Ball (1994), que a política é ajustada, criativamente, em contexto local conforme os sujeitos se esforçam, ou não, para lhe dar respostas.

174 Educação \& Realidade, Porto Alegre, v. 43, n. 1, p. 171-186, jan./mar. 2018. 
Quando os professores e coordenadores das três licenciaturas foram inquiridos sobre sua participação e atuação no processo de reformulação curricular exigida pelas agências oficiais e pela instituição, suas narrativas foram bastante parecidas: falta tempo!

Falta tanta coisa! Primeiro tempo! São reuniões e reuniões, orientações, TCC, muitos alunos, muita carga horária, projetos, as funções administrativas... E a Pós só piora. A Pós tem tomado muito tempo dos professores: muito espaço, muito tempo. Quando se faz um concurso é para o departamento; é tanto para graduação quanto para pós-graduação; não é só para uma ou só para outra, tem que ter uma visão do todo. Isso dificulta muito de se fazer reuniões, de se encontrar para discutir o trabalho de cada um e o currículo. Os professores precisam dar conta de muita coisa hoje! (SN, 2015).

O NDE veio para complementar, não que o colegiado não tenha essa parte pedagógica, é que não conseguia fazer, não dava tempo... A questão é que não se tem mais tempo para fazer tudo; nem o NDE tem esse tempo, hoje temos muito trabalho e cada um vai para um lado apagar o fogo. Até para marcar uma reunião é difícil... A gente começa as coisas, tudo bem... Mas, quando vamos nos encontrar novamente, já passou muito tempo... É sempre um recomeço; não anda... Eu acho que, realmente, ele está auxiliando porque são mais cabeças pensantes com os mesmos propósitos e com responsabilidade de fazer. Então, o NDE tem essa responsabilidade e ele busca isso. Isso eu acho legal e acho que tem melhorado bastante, mas, te digo, não tá muito fácil (EF, 2015).

Os debates feitos são muito superficiais do ponto de vista da questão da formação. Lidamos nesses espaços com coisas pontuais. Depende muito do tempo das pessoas também; é tudo muito corrido... Ninguém para pensar e, também, são poucos que querem pensar a licenciatura, reunir para discutir o currículo... São tantas outras coisas... Não se avançou, entende? (EV, 2015).

O grande problema que enfrentamos, eu acho, é a carga de trabalho, são muitas tarefas, aulas (graduação, especialização, mestrado), trabalhos, provas, pesquisas, relatórios, reuniões, NDE, colegiado, burocracias... Isso dificulta o andamento dos encontros e das discussões... O NDE quase não se reúne mais... Porque é difícil; cada um tem uma coisa... Não tem como... Não sei... (SP, 2015).

Estudos sobre a formação e o trabalho docente têm caracterizado essa rotina da docência como um processo de intensificação do trabalho. Com a expansão crescente dos cursos superiores, além do trabalho já estabelecido nas instituições (aulas, representações em colegiados e comissões, reuniões, estágios e orientações - trabalhos de conclusão, iniciação à pesquisa, extensão, etc.) aumentaram, também, as demandas de trabalho e o número de alunos a serem atendidos; emergiram as novas políticas oficiais (PIBID, PACTOs, Educação a Distância, PARFOR, etc.) que implicam e responsabilizam os professores formadores com seu desenvolvimento; ainda, por este caminho, os professores formadores são atraídos por diferentes bolsas (de pesquisa, de trabalho, de projetos); insta-se a cultura dos editais de financiamentos para pesquisas e o professor formador, ao entrar nesse jogo, é amarrado pelos prazos, pela gestão dos recursos, pelo desenvolvimento de pesquisa de curto e 
longo prazo, pela prestação de contas dos recursos e das análises dos dados. É esperado desse professor que, também, crie, organize, mantenha grupo de pesquisa, publique em livros e revistas de excelência da sua área de atuação; que, de preferência, integre-se a um programa de pós-graduação e que assuma as demandas que ali se estabelecem.

Certamente, essa dinâmica atual do trabalho do professor reflete num processo de intensificação do seu trabalho, mas, sobretudo, sugiro que é mais do que isso. O que está em questão é a constituição de novos sujeitos, os quais devem ser capacitados para viver e fazer conforme as exigências atuais e, neste sentido, como qualquer outro ser humano, o professor formador de professores não pode ficar fora do jogo. É interessante, antes de qualquer coisa, lembrar-se de dois aspectos: primeiro, que o trabalho docente é muito mais do que uma simples expressão, é uma categoria social altamente disputada devido ao papel que ocupa produção de outras condutas profissionais, legitimação de concepções, de significado, de representações e produção de conhecimento na sociedade capitalista; segundo, como categoria social, vinculada à identidade profissional, deve ser vista como uma prática historicamente contextualizada, ou seja, como imanente da dinâmica e dos interesses sociais vigentes.

Como ensinou Foucault (2002), cada época define, enquadra, delimita, regula e governa os discursos e os saberes; portanto, cada época envolve uma ordem de possibilidades e impossibilidades. Toda sociedade tem sonhos, fabrica desejos e intenções a serem alcançados; neste sentido, necessita criar e produzir meios de inserir seus membros em um regime de racionalidades para que tenha sucesso. Em tempos de governamentalidade neoliberal e seus imperativos, a questão do controle dos profissionais requer outras tecnologias para governar as condutas, cada vez mais, a distância. Assim, realocar o conceito de profissão no interior de outras orientações e esperanças facilita a operacionalização de práticas que se dirigem a governar e a controlar sujeitos específicos.

Na mesma condição em que se deseja transformar e criar, social e culturalmente, uma nova ordem para a profissão do professor da Educação Básica, está em jogo, também, novas exigências para a profissão do professor que exerce a docência no Ensino Superior. Aliás, o que está em movimento é um conjunto de práticas mais amplas (novas transformações do trabalho, da economia, do mercado e do consumo) que tentam incutir, na conduta de todo e qualquer sujeito, a mentalidade desta época, a qual urge por um novo tipo sujeito: consumidor, individualista, flexível, autogovernado e um competidor ativo.

Portanto, aquele sentimento apontado pelos professores formadores anteriormente (falta de tempo, dificuldade de se reunirem, muito trabalho, várias tarefas) talvez possam ser considerados como um movimento que, aos poucos e sutilmente, vem criando e produzindo uma racionalidade para o professor formador e seu trabalho. Quero dizer que esse processo que intensifica o trabalho é muito mais um sintoma das novas condições que se colocam para o trabalho no ensino superior do que a sua causa primeira.

176 Educação \& Realidade, Porto Alegre, v. 43, n. 1, p. 171-186, jan./mar. 2018. 
Os estudos de Ball (2002; 2005; 2012) têm contribuído, sobremaneira, para se compreender essa questão da profissão docente no contexto desta sociedade. Segundo esse pesquisador, a concepção de profissão está sendo deslocada; ou seja, o profissional autêntico está dando espaço para o profissional reformado (aquele que começa a ser o tipo de sujeito requerido atualmente). Para Ball (2012), a concepção de profissional autêntico conjugava ideias voltadas para prática ética-cultural, a ambiguidade e o pluralismo (relação especial entre o que trabalha e seu trabalho, uma relação compromissada com princípios internos e coletivos, busca por reflexões e tomadas de decisões corretas, respeito, etc.); já, a atual concepção de profissionalismo emerge vinculada a questões mais técnicas do trabalho do professor. Diz Ball (2012, p. 35),

Com todos os perigos modernistas que existem, vou me referir ao profissional pré-reforma - como um profissional autêntico. Quando a autenticidade está baseada no valor da reflexão e na possibilidade sempre presente de indecisão [...] mas uma vez que as possibilidades de reflexão moral, de diálogo e de indecisão são erradicadas, as possibilidades de profissionalização então estão, na verdade, erradicadas. [...] Os pontos chave de diferença, ou no mínimo dois deles, são [...] que estes 'pós-profissionalismos' são, em última análise redutíveis a exogenamente gerados, seguidores de regras, e, em segundo lugar, que eles traduzem o profissionalismo numa forma de performance onde o que conta como prática profissional depende do satisfazer às decisões fixas impostas externamente. Os critérios de qualidade ou de boa prática aqui são estanques e completos - em oposição '[...] à necessidade de raciocínio moral e à incerteza adequada' (Lambek, 2000) como características definitivas da prática profissional.

No quadro desse movimento, essa nova racionalidade técnica (Ball, 2012) caracteriza-se por incentivar a constituição de profissionais da educação, também, como técnicos, que exerçam o seu trabalho dando prioridade para condições eminentemente pragmáticas e individuais (com base no autogoverno, autoconfiança, autodisciplina, autoatualização, autorresponsabilidade, etc.). Por esse viés e atrelando às falas anteriores dos professores formadores, fica clara a associação com um tipo de trabalho docente que começa a ser conduzido pelo princípio do individualismo empreendedor; ou seja, os professores estão tão envolvidos com suas práticas privadas, urgentes e com os meios de gerenciá-las, que pouco tempo sobra para pensar, discutir e reformar, de forma coletiva, os currículos das licenciaturas.

No modo como os caminhos se abrem, sutilmente, na dinâmica travestida de flexível, aberta, inovadora, necessária, faz parecer que os rumos apontam para novas liberdades de escolhas. Ou seja, parece, simplesmente, que, no contingente das possibilidades existentes, os professores formadores escolhem o que devem fazer e como. No entanto, um princípio cada vez mais privado vai sendo incluído e vai imprimindo, silenciosamente, na alma destes professores, um sistema de 
significados no qual um novo tipo de professor é construído. Embora Ball (2012) fale de sua realidade quanto à emergência de outra forma de profissionalismo docente, talvez se possa pensar se não estamos nos aproximando desse tipo de profissionalismo técnico; para o qual um tipo especial de sujeito é necessário: que responda aos estímulos de forma pragmática, técnica e individual, e não como um sujeito reflexivo e crítico preocupado com questões humanistas, cooperativas e coletivas. Parece que o que está em jogo é a constituição de um sujeito privado; ou seja, o bom professor é aquele flexível, aberto às propostas e, principalmente, aquele que batalha individualmente para se tornar a cada dia melhor (mais qualificado, mais atualizado, mais produtivo...). Nesse processo, questões de compromisso com o bem comum, questões pedagógicas, estéticas, valores, metas cognitivas e complexidade política vão, aos poucos, perdendo espaço na agenda; no caso específico da reforma do currículo, esse sujeito formador tem se ocupado da função de um técnico capacitado para fazer funcionar e dar respostas para algo que foi construído e organizado por outros (MEC, CAPES, programas, políticas, avaliações, editais, coordenadores de curso, etc.).

Nessas condições, parece que os professores formadores, ao mesmo tempo em que estão se constituindo como novos tipos de profissionais, estão, também, se afastando, cada vez mais, das possibilidades de interferirem na produção dos currículos. Apresento, nos próximos parágrafos, três exemplos significativos que oferecem base a essa afirmação.

O primeiro exemplo é a maneira como os currículos das licenciaturas e as questões pedagógicas vêm sendo tratadas no interior dos cursos investigados. Basicamente, nossos estudos têm mostrado as dificuldades encontradas pelo corpo docente para discutir, avaliar e reformar as licenciaturas, pois, como dito anteriormente, outras questões são tidas como mais fundamentais. Temos verificado, em pesquisas, que as reformas dos currículos, nessa mesma instituição e nos mesmos cursos, ficaram sob responsabilidade exclusiva dos coordenadores e de alguns colaboradores eventuais. Essa condição, como mostram os exemplos abaixo, parece que não se modificou:

Eu não participei desse processo de reformulação. [...]. Quem se dedicou a isso foi a [...] coordenadora, ela, praticamente, fez o currículo... Tomou essa responsabilidade da reformulação (A2, 2015).

Acho que nem sou eu que devo falar sobre isso porque foi a professora a [...] coordenadora que reescreveu, reestruturou; a professora foi responsável por tudo isso aqui na verdade. Isso é bem claro aqui. [...]. Qual foi o meu trabalho? E não é pouco... Trabalho de levar de lá pra cá. Tenho que fazer com que isso que foi feito se torne realidade prática porque, até esse momento, era só teoria (A2, 2015).

O próprio texto das diretrizes não é conhecido pela maioria dos professores do curso. Fica tudo com o coordenador, não há um envolvimento dos professores para tratar da licenciatura. Acaba ficando um remendo que os coordenadores fazem porque tem que fazer para cumprir o que é pedido, é assim...! (S1, 2015). 
[...] Olha, há uma discussão sobre o projeto pedagógico; há uma discussão, mas não anda. Por uma série de problemas (tempo é um deles), hoje, temos muitas outras coisas/tarefas... Ela tem tido certa estagnação, mas começou, se me lembro, desde 2011. Começou quando o professor [?] era coordenador e, quando ele saiu para fazer o Pós-doc, deu uma baixa. Claro que não deveria ser assim e tudo, mas...! A gente dizia, na época, que um processo desse tipo não depende de um professor, mas deu, deu uma baixa. Depois queriam uma transição, e o professor que ficou como coordenador temporariamente não conseguiu levar adiante e, depois, entrou a coordenadora atual que tenta, também, mas está muito estagnado (S2, 2015).

É... Bom.... Eu não tenho muito a dizer sobre como foi feito essa mudança. Lembro que houve algumas poucas conversas, mas quem pode dar maiores informações é o coordenador daquele momento. Ele é o colega [...] encaminharam isso, fizeram as reformas mesmo, depois apresentaram numa reunião e discutimos e aprovamos. É isso que lembro... Que posso te dizer... (M3, 2015).

O segundo exemplo, trata da política institucional que tenta pensar e organizar, de forma coletiva, os cursos de licenciatura. Durante o ano de 2014, uma comissão foi organizada na instituição com o objetivo de realizar um trabalho de articulação entre as diferentes licenciaturas e discuti-las. Contudo, nas variadas tentativas de se marcarem reuniões e provocar o debate, essa comissão não obteve sucesso em congregar um quórum mínimo de representantes dos 25 cursos de licenciaturas para iniciar a discussão, avaliar as ações e pensar novas condições. Neste mesmo ano, também, organizamos um evento, em parceria com três cursos de licenciaturas que faziam parte dos nossos estudos, com o objetivo de apresentar, compartilhar e discutir, com professores e alunos desses cursos, as análises que havíamos desenvolvido. Durante o evento, as aulas foram canceladas e conseguimos transporte da instituição para que professores, coordenadores e alunos pudessem participar dos três dias de atividades. Para nossa surpresa, a grande maioria dos alunos esteve presente (os quais foram dispensados das aulas com obrigatoriedade de estarem no evento e receberem certificados). Dos 55 professores formadores, que constituem os três cursos, computamos um número de oito professores formadores presentes em todo o evento.

O terceiro exemplo diz respeito ao funcionamento do Núcleo Docente Estruturante (NDE). O NDE, conforme a Resolução no 1 de junho de 2010 (Brasil, 2010), é um colegiado de professores com atribuições acadêmicas de acompanhamento, desenvolvimento, organização e avaliação do projeto pedagógico dos cursos de graduação. O NDE emerge, basicamente, com a justificativa de que os colegiados de cursos, pela vasta responsabilidade com questões mais administrativas, acabam por deixar para segundo plano as questões de ordem pedagógicas. Os professores que participaram desta pesquisa, que são membros destes núcleos, insistiram em dizer que tem sido muito difícil manter um ritmo permanente de trabalho e dar conta das atribuições que são exigidas para esse núcleo, inclusive a reforma dos currículos. Segundo os coordenadores, tem sido difícil, pela carga de trabalho, convencer os 
professores a participarem de mais um colegiado e promover um amplo e coletivo trabalho sobre as licenciaturas. A solução encontrada pelos cursos vem sendo de concentrar o mesmo grupo de representantes no Colegiado e no NDE; ou seja, a ideia de ter um grupo mais envolvido com as questões pedagógicas das licenciaturas parece não ter sido uma prática efetiva nos espaços dessas licenciaturas. Por esse ritmo, os professores formadores, como já dito, vão se constituindo em técnicos (operadores) de currículos.

Esse significado para a prática docente (mais técnica e operacional) que se verifica no contexto do trabalho nas instituições superiores, também, pode ser verificado no discurso do texto da política curricular (DCN). Nossas observações demonstraram que, pelo discurso das DCN, essa centralidade, na prática, aparece, mais profundamente, com a ideia de competência como eixo ou guia articulador da formação e como algo que deve ser provado, posteriormente, no trabalho docente. Embora o parecer do CNE busque justificar a aposta no uso de competência como fonte fundamental para uma nova formação e que ela deve permitir uma articulação entre teoria e prática, o que se observa, no conjunto do texto e na resolução que implementa as diretrizes, é que a questão da prática tende a ser mais forte (Dias; Lopes, 2009; Garcia; Fonseca; Leite, 2013). Mais do que isso, como salientam Dias e Lopes (2009, p. 87-88),

[...] a prática é um discurso aglutinador para a formação de professores, pois ele pressupõe um antagonismo a um saber teórico. Embora circulem proposições com ressalvas quanto a uma prevalência da prática em relação ao conhecimento teórico, essa teoria só é valorizada se tem a prática como ponto de referência e de finalidade [...] mesmo no discurso crítico de um possível aligeiramento teórico, a prática predomina como definidora dessa mesma teoria, mantendo o antagonismo entre teoria e prática. Se a teoria precisa ser defendida para a sua afirmação no currículo, é um indicador de estar havendo um deslocamento de sua importância nas propostas que vêm sendo forjadas para a formação docente.

Essa relação parece passar despercebida, pois a concepção de competência se tornou, no campo da educação, uma expressão banal que é repetida sem ser contextualizada. No texto Competências na Formação de Professores no Brasil: o que (não) há de novo, Dias e Lopes (2003) problematizam o conceito de competência, argumentando que esse não é um conceito novo, pois vem sendo empregado na teoria curricular ao longo dos tempos. Contudo, há que se compreender que o conceito de competência é imanente ao processo histórico, social, cultural, econômico e, também, ao que se espera da educação em cada época. Atualmente, segundo Dias e Lopes, competência está associada à relação que se estabeleceu, a partir das reformas dos anos de 1990, entre educação e mercado; é um conceito que tem sido reforçado no conjunto de práticas (avaliação por desempenho, promoção dos professores por mérito, conceitos de produtividade, eficiência, eficácia) que buscam sustentar 
essa relação de viés econômico no campo da educação. Pela concepção atual de competências “[...] mais que dominar conhecimentos teóricos, importa que o professor saiba aplicar esse conhecimento em situações concretas" (Dias; Lopes, 2003, p. 1171).

Assim, pelo viés da competência, a prioridade é para uma formação que contemple habilidades que possam instrumentalizar o professor para agir em situação de resolução de problemas técnicos, especialmente, no que tange ao desempenho dos alunos. Outros exemplos desse foco na prática permeiam o texto das diretrizes. Estas apresentam críticas que apontam para uma formação muito teórica no espaço das licenciaturas e indicações para a ampliação da carga horária: mínimo de 2800 horas constituídas de 400 horas de prática como componente curricular, vivenciadas ao longo do curso; 400 horas de estágio curricular supervisionado a partir do início da segunda metade do curso; 1800 horas de aulas para os conteúdos curriculares de natureza científico-cultural; 200 horas para outras formas de atividades acadêmicas científico-culturais. É importante considerar que essa carga horária antecipa a ida dos alunos para o interior das escolas, já, no meio dos cursos e focaliza a formação dos futuros professores no fazer docente.

No espaço dos cursos investigados, parece que esse discurso das diretrizes encontrou um ninho acolhedor, pois algumas ações já existentes permitiram que o foco na prática fosse reforçado como princípio da formação. Antes de qualquer coisa, vale salientar que a estratégia utilizada para as reformas dos currículos foi a de uma política de ajustes para dar conta daquilo que as DCN exigiam em termos de carga horária. $\mathrm{O}$ ajuste não fugiu do modelo tradicional que se tem observado nas reformas curriculares nos últimos tempos: sem um diagnóstico dos cursos, sem a relação com as novas transformações sociais, sem discussões amplas e profundas sobre o currículo de formação docente; e sem que, sequer, o texto das DCN fosse analisado ou causasse interesse aos alunos e professores. No caso do curso de Educação Física, por exemplo, havia, no currículo anterior, três disciplinas para tratar do conteúdo de dança e três para o de futebol. Com a reforma, essas disciplinas foram reduzidas para apenas uma e, também, foi retirada desse currículo a disciplina de Sociologia; atividades que aconteciam de forma mais livre (pesquisa, intervenções, disciplinas optativas) receberam nome de Prática Como Componente Curricular e foram incorporadas na nova grade. No caso dos outros cursos, salvo algumas pequenas diferenças, a situação foi muito parecida, i.e., foi mantida a tradição de formação com pequenos ajustes para adaptar a carga horária.

Sugiro que as condições que se apresentam para a atuação do trabalho do professor formador, atualmente, têm favorecido uma íntima relação com algumas esperanças movimentadas pelo discurso promovido pela política curricular. Enrolados num processo de trabalho intenso, dinâmico, exaustivo, cada vez mais individual, certamente, há que se concordar com os professores de que falta tempo para se dedicar, profundamente, ao estudo das diretrizes e suas intenções, ao diagnóstico dos currículos vigentes, às condições da formação; também, ao 
planejamento, às discussões, ao acompanhamento e às reformas dos currículos.

Do que pode ser percebido a partir dos dados desta pesquisa, existem bons indicativos de que, nesses cursos, a combinação entre as condições de trabalho dos formadores e os discursos das diretrizes tem favorecido, também, as condições para que os princípios de uma racionalidade prática se configurem como centrais para a formação de professores. Não se pode esquecer, seguindo as pistas dos estudos sobre o currículo (Silva, 1996; 1999a; 1999b; 1999c; Corazza, 2001), que os discursos e as experiências que se corporificam neste espaço asseguram o sentido da intimidade estreita entre formação, identidade e subjetividade (Silva, 1996). Em outras palavras, aquilo que consta nos currículos tem impactos na vida daqueles que o vivenciam. O currículo é um espaço especial de produção e governo das subjetividades, de sua adaptação e acomodação. As disciplinas e as narrativas que o currículo coloca em ação definem comportamentos, atitudes; impõem conceitos, significados e representações como sendo as melhores, as mais importantes. Assim, essas disciplinas e narrativas dividem, hierarquizam, posicionam e julgam o que é mais ou menos importante para a formação dos professores. Deste ponto de vista, é impossível pensar o currículo sem concebê-lo como envolvido em relações de poder que produzem e estruturam o eventual campo de ação dos outros (Foucault, 1990) e dos demais sujeitos envolvidos no processo. Portanto, quem tem o poder de planejar, fazer escolhas, discutir, desenvolver e avaliar o currículo das licenciaturas, ou de não se dedicar a esse conjunto de tarefas, deixando-as nas mãos de outrem, tem, também, uma parcela de poder sobre a criação das condutas (subjetividades e identidades) de si e dos futuros professores.

A relação entre os professores formadores e as reformas realizadas a partir da política curricular se constituiu, como se pode observar até aqui, de um jogo de duplo sentido: professores formadores pouco se envolveram no processo de discussão e reforma dos currículos; nesta condição, estes se colocaram como meros operadores de projetos implementados pelos coordenadores e alguns poucos professores. O que parece não ser considerado neste jogo é que as novas condições de trabalho dos formadores e seus desinteresses (ou dificuldades para se envolverem) com a reforma curricular são sintomas de que, aos pouquinhos, eles mesmos estão ajudando a produzir uma armadura para suas condutas docentes (Foucault, 2003); esta, também, mais técnica e operacional.

Diante do que foi problematizado, parece que é da ordem das nossas responsabilidades avaliar e discutir sobre a relação entre reformadores de currículos e sua condição no campo da formação docente. Embora o texto se detenha a cursos específicos, creio que algumas questões, aqui apresentadas, nos fazem refletir: quem somos e o que fazemos como professores formadores de professores? Como compreendemos o currículo? Qual a nossa implicação com as reformas curriculares? Que significados, representações, imagens, de formação de 
professores, de trabalho docente e de Educação Básica, assumimos e fazemos circular?

Atualmente, este exercício reflexivo (sobre o que somos e o que estamos fazendo como professores que se dedicam a formar professores) se torna mais importante, pois está em andamento, com a resolução CNE/CP 2/2015 (Brasil, 2015), a nova política curricular, que deve ser implementada até meados de 2018. Como já dito por Foucault (1995), nem tudo é ruim, mas tudo é perigoso e se existe perigo temos muito que fazer. Refutar o que somos, desconfiar de nós mesmos, das nossas crenças, das nossas ações e opções talvez seja uma boa iniciativa para que possamos, por outros meios e perspectivas, ensaiar e promover lutas e reinvindicações por novas formas de ser professor e formar professores. Que, sobretudo, possamos ser parte das reformas das licenciaturas como inventores de currículos e não como técnicos operadores de algo definido por outros.

Recebido em 07 de janeiro de 2016 Aprovado em 07 de agosto de 2017

\section{Referências}

BALL, Stephen. What is Policy? texts, trajectories and toolboxes. In: BALL, Stephen. Education Reform: a critical and post-structural approach. Buckingham: Open University Press, 1994. P. 14-27.

BALL, Stephen. Diretrizes Políticas Globais e Relações Políticas Locais em Educação. Currículo sem Fronteiras, Braga, v. 1, n. 2, p. 99-116, jul./dez. 2001. Disponível em: <http://www.curriculosemfronteiras.org/volliss2articles/ball. pdf $>$. Acesso em: 2 jan. 2010.

BALL, Stephen. Reformar Escolas/Reformar Professores e os Terrores da Perfomatividade. Revista Portuguesa de Educação, Braga, v. 15, n. 2, p. 3-23, 2002. Disponível em: <http://josenorberto.com.br/BALL.\%2037415201.pdf>. Acesso em: 6 abr. 2000.

BALL, Stephen. Profissionalismo, Gerencialismo e Perfomatividade. Cadernos de Pesquisa, São Paulo, v. 35, n. 126, p. 539-564, set./dez. 2005. Disponível em: <http://www.scielo.br/pdf/cp/v35n126/a02n126.pdf>. Acesso em: 11 dez. 2009.

BALL, Stephen. Reforma Educacional como Barbárie Social: economismo e o fim da autenticidade. Práxis Educativa, Ponta Grossa, v. 7, n. 1, p. 33-52, jan./ jun. 2012. Disponível em: <http://www.revistas2.uepg.br/index.php/praxiseducativa/article/view/4003/2807>. Acesso em: 3 fev. 2013.

BRASIL. Ministério da Educação. Parecer n CNE/CP 009/2001. Diretrizes Curriculares Nacionais para a Formação de Professores da Educação Básica, em nível superior, curso de licenciatura, de graduação plena. Diário Oficial da União, Brasília, 18 jan. 2002a. P. 31. Disponível em: <http://portal.mec.gov.br/cne/arquivos/pdf/009.pdf>. Acesso em: 5 fev. 2005.

BRASIL. Ministério da Educação. Parecer nº CNE/CP 28/2001. Dá nova redação ao Parecer CNE/CP 21/2001, que estabelece a duração e a carga horária dos cursos de Formação de Professores da Educação Básica, em nível superior, curso de licenciatura, de graduação plena. Diário Oficial da União, Brasília, 18 jan. 2002b. P. 31. Disponível em: <http://portal.mec.gov.br/cne/arquivos/pdf/028. pdf>. Acesso em: 5 fev. 2005.

Educação \& Realidade, Porto Alegre, v. 43, n. 1, p. 171-186, jan./mar. 2018. 
Diretrizes Curriculares e Professores Formadores

BRASIL. Ministério da Educação. Resolução CNE/CP 1, de 18 de fevereiro de 2002. Institui Diretrizes Curriculares Nacionais para a Formação de Professores da Educação Básica, em nível superior, curso de licenciatura, de graduação plena. Diário Oficial da União, Brasília, 9 abr. 2002c. P. 31. Disponível em: <http:// portal.mec.gov.br/cne/arquivos/pdf/rcp01_02.pdf>. Acesso em: 5 fev. 2005.

BRASIL. Ministério da Educação. Resolução CNE/CP 2, de 19 de fevereiro de 2002. Institui a duração e a carga horária dos cursos de licenciatura, de graduação plena, de formação de professores da Educação Básica em nível superior. Diário Oficial da União, Brasília, 4 mar. 2002d. P. 9. Disponível em: <http://portal.mec.gov.br/cne/arquivos/pdf/CP022002.pdf>. Acesso em: 5 fev. 2005.

BRASIL. Resolução n. 1 de 17 de junho de 2010. Normatiza o Núcleo Docente Estruturante e dá outras providências. Comissão Nacional de Avaliação da Educação Superior, Brasília, 17 de jun. 2010.

BRASIL. Ministério da Educação. Resolução CNE/CP 2, de $1^{\circ}$ de julho de 2015. Define as Diretrizes Curriculares Nacionais para a formação inicial em nível superior (cursos de licenciatura, cursos de formação pedagógica para graduados e cursos de segunda licenciatura) e para a formação continuada. Diário Oficial da União, Brasília, 2 de julho de 2015. P. 8.

CORAZZA, Sandra. Que Quer um Currículo? Pesquisa pós - críticas em educação. São Paulo: Vozes, 2001.

DIAS, Rosanne Evangelista; LOPES, Alice Casimiro. Competências na Formação de Professores no Brasil: o que (não) há de novo. Educação \& Sociedade, Campinas, v. 24, n. 85, p. 1155-1177, dez. 2003. Disponível em: <http://www.scielo.br/pdf/es/v24n85/a04v2485.pdf>. Acesso em: 3 fev. 2005.

DIAS, Rosanne Evangelista; LOPES, Alice Casimiro. Sentidos da Prática nas Políticas de Currículo para a Formação de Professores. Currículo sem Fronteiras, Braga, v. 9, n. 2, p. 79-99, jul./dez. 2009. Disponível em: <http://www.curriculosemfronteiras.org/vol9iss2articles/dias-lopes.pdf>. Acesso em: 24 maio 2010.

FOUCAULT, Michel. O Sujeito e o Poder. In: DREYFUS, Hubert; RABINOW, Paul. Michel Foucault, uma Trajetória Filosófica: para além do estruturalismo e da hermenêutica. Rio de Janeiro: Graal, 1990. P. 273-295.

FOUCAULT, Michel. Sobre a Genealogia da Ética: uma revisão do trabalho. In: RABINOW, Paul; DREYFUS, Hubert. Michel Foucault: uma trajetória filosófica (para além do estruturalismo e da hermenêutica). Rio de Janeiro: Forense Universitária, 1995. P. 253-278.

FOUCAULT, Michel. A Ordem do Discurso. Tradução: Laura Fraga de Almeida Sampaio. São Paulo: Loyola, 2002.

FOUCAULT, Michel. História da Sexualidade 2: o uso dos prazeres. Tradução: Maria Thereza da Costa Albuquerque. Rio de Janeiro: Graal, 2003.

FOUCAULT, Michel. Nascimento da Biopolítica. Tradução: Eduardo Brandão. São Paulo: Martins Fortes, 2008a.

FOUCAULT, Michel. Segurança, Território, População. Tradução: Eduardo Brandão. São Paulo: Martins Fortes, 2008b.

GARCIA, Maria Manuela Alves. O Sujeito Emancipado nas Pedagogias Críticas. Educação \& Realidade, Porto Alegre, v. 26, n. 2, p. 31-50, jul./dez. 2001.

GARCIA, Maria Manuela Alves. O Intelectual Educacional e o Professor Críticos: o pastorado das consciências. Currículo Sem Fronteiras, Braga, v. 2, n. 2, p. 5378, jul./dez. 2002a. Disponível em: <http://www.curriculosemfronteiras.org/ vol2iss2articles/manuela.pdf>. Acesso em: 3 dez 2009.

184 Educação \& Realidade, Porto Alegre, v. 43, n. 1, p. 171-186, jan./mar. 2018. 
GARCIA, Maria Manuela Alves. Pedagogias Críticas e Subjetivação: uma perspectiva foucaultiana. Petrópolis: Vozes, 2002b.

GARCIA, Maria Manuela Alves; FONSECA, Márcia Souza da; LEITE, Vanessa Caldeira. Teoria e Prática na Formação de Professores: a prática como tecnologia do eu docente. Educação em Revista, Belo Horizonte, v. 29, n. 3, p. 233264, set. 2013. Disponível em: <http://www.scielo.br/pdf/edur/v29n3/a10v29n3. pdf $>$. Acesso em: 20 out. 2013.

POPKEWITZ, Thomas. Profissionalização e Formação de Professores: algumas notas sobre a sua história, ideologia e potência. In: NÓVOA, António. Os Professores e a sua Formação. Lisboa/Portugal: Publicações Dom Quixote, 1992. P. 37-50.

POPKEWITZ, Thomas. Reforma Educacional e Construtivismo. In: SILVA, Tomaz Tadeu (Org.). Liberdades Reguladas: a pedagogia construtivista e outras formas de governo do eu. Petrópolis: Vozes, 1999. P. 95-142.

POPKEWITZ, Thomas. Lutando em Defesa da Alma: a política do ensino e a construção do professor. Tradução: Magda França Lopes. Porto Alegre: ARTMED, 2001.

POPKEWITZ, Thomas; OLSSON, Ulf; PETERSSON, Kenneth. Sociedade da Aprendizagem, Cosmopolitismo, Saúde Pública e Prevenção à Criminalidade. Educação \& Realidade, Porto Alegre, n. 34, v. 2, p. 73-96, maio/ago. 2009. Disponível em: <http://seer.ufrgs.br/educacaoerealidade/article/viewFile/8309/5541>. Acesso em: 9 nov. 2010.

POPKEWITZ, Thomas. Números em Grades de Inteligibilidade: dando sentido à verdade educacional. In: TURA, Maria de Lourdes Rangel; GARCIA, Maria Manuela Alves. Currículo, Política e Ação Docente. Rio de Janeiro: EdUERJ, 2013. P. 19-50.

ROSE, Nikolas. Governing ‘Advanced' Liberal Democracies. In: BARRY, Andrew; OSBORNE, Thomas; ROSE, Nikolas (Ed.). Foucault and Political Reason: liberalism, neo-liberalism and rationalities of government. Chicago: The University Chicago Press, 1996. P. 37-64.

ROSE, Nikolas. Governando a Alma: a formação do eu privado. In: SILVA, Tomaz Tadeu da (Org.). Liberdades Reguladas: a pedagogia construtivista e outras formas de governo do eu. Rio de Janeiro: Vozes, 1998. P. 30-45.

ROSE, Nikolas. Como se Deve Fazer a História do Eu? Educação \& Realidade, Porto Alegre, v. 26, n. 1, p. 33-57, jan./jul. 2001.

SILVA, Tomaz Tadeu da. Identidades Terminais: as transformações na política da pedagogia na pedagogia da política. Rio de Janeiro: Vozes, 1996.

SILVA, Tomaz Tadeu da (Org.). Liberdades Reguladas: a pedagogia construtivista e outras formas de governo do eu. Petrópolis: Vozes, 1999a.

SILVA, Tomaz Tadeu da. Documentos de Identidade: uma introdução às teorias do currículo. Belo Horizonte: Autêntica, 1999b.

SILVA, Tomaz Tadeu da. O Currículo como Fetiche: a poética e a política do texto curricular. Belo Horizonte: Autêntica, 1999c.

VEIGA-NETO, Alfredo. Educação e Governamentalidade Neoliberal: novos dispositivos, novas subjetividades. In: PORTOCARRERO, Vera; CATELO BRANCO, Guilherme (Org.). Retrato de Foucault. Rio de Janeiro: NAU, 2000. P. 179-217.

VEIGA-NETO, Alfredo. Coisas do Governo. In: RAGO, Margareth; ORLANDI, Luiz Lacerda; VEIGA-NETO, Alfredo (Org.). Imagens de Foucault e Deleuze: ressonâncias neitzchianas. Rio de Janeiro: DP\&A, 2002. P. 13-34.

VEIGA-NETO, Alfredo. Crise da Modernidade e Inovações Curriculares: da disciplina para o controle. In: ENCONTRO NACIONAL DE DIDÁTICA E PRÁTICA DE ENSINO (ENDIPE), 14., 2008, Porto Alegre. Anais... Porto Alegre: 2008. P. 35-58.

Educação \& Realidade, Porto Alegre, v. 43, n. 1, p. 171-186, jan./mar. 2018. 
Mara Rejane Vieira Osório é bacharel e licenciada em Ciências Sociais, Doutora em Educação, Professora da Faculdade de Educação (Departamento de Ensino) e do PPGE da UFPel. Lider do Grupo de Estudos sobre Docência e Educação Básica: currículo, politicas e profissionalização docente (GEDEB).

E-mail:mareos@gmail.com 